\title{
Phase I study of vemurafenib in children with recearch Paper progressive BRAFV600 mutant brain tumors: Pacific Pediatric Neuro-Oncology Consortium study (PNOC-002)
}

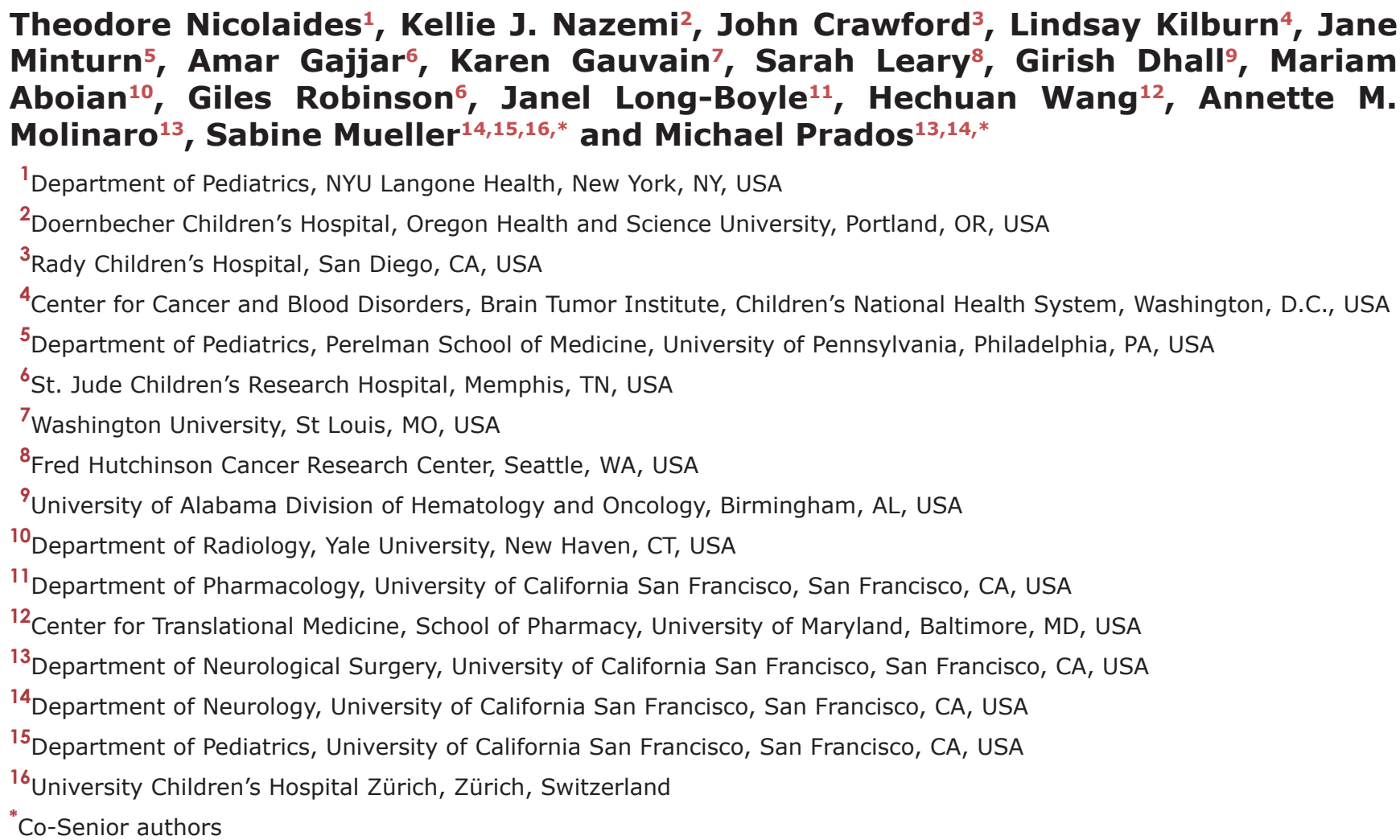
Minturn', Amar Gajjar, Karen Gauvain7, Sarah Leary ${ }^{6}$, Girish Dhall9, Mariam Aboian $^{10}$, Giles Robinson ${ }^{6}$, Janel Long-Boyle ${ }^{11}$, Hechuan Wang ${ }^{12}$, Annette $M$. Molinaro $^{13}$, Sabine Mueller ${ }^{14,15,16, *}$ and Michael Prados ${ }^{13,14, *}$

Correspondence to: Theodore Nicolaides, email: Theodore.Nicolaides@nyulangone.org Michael Prados, email: Michael.prados@ucsf.edu

Keywords: BRAFV00E; pediatric glioma; vemurafenib; clinical trial

Received: March 03, $2020 \quad$ Accepted: April 27, $2020 \quad$ Published: May 26, 2020

Copyright: Nicolaides et al. This is an open-access article distributed under the terms of the Creative Commons Attribution License 3.0 (CC BY 3.0), which permits unrestricted use, distribution, and reproduction in any medium, provided the original author and source are credited.

\section{ABSTRACT}

Background: BRAF ${ }^{\mathrm{V} 600 \mathrm{E}}$ mutation is present in a subset of pediatric brain tumors. Vemurafenib is an oral, selective ATP-competitive inhibitor of BRAF ${ }^{\mathrm{V} 600}$ kinase. The goal of this multi-center study conducted through the Pacific Pediatric Neuro-Oncology Consortium (PNOC) was to determine the recommended phase 2 dose (RP2D) and dose limiting toxicities (DLTs) in children $<18$ years with recurrent or progressive BRAF $^{\mathrm{V} 600 \mathrm{E}}$ mutant brain tumors.

Results: Nineteen eligible patients were enrolled. Eleven patients had received three or more prior therapies. Data reported are from the start of treatment for the first patient (April 30 2014) through August 31 2019. The RP2D was defined as $550 \mathrm{mg} / \mathrm{m}^{2}$ twice daily after DLT criteria adjustment for rash. Related grade $\geq 3$ adverse events included secondary keratoacanthoma $(n=1)$; rash $(n=16)$; and fever $(n=5)$. Subjects received a median of 23 cycles (range 3-63). Four patients remain 
on treatment. Centrally reviewed best radiographic responses included 1 complete response, 5 partial responses, and 13 stable disease. The steady-state area under the curve (AUC ${ }_{0-\infty}$ median) was $604 \mathrm{mg} * \mathrm{~h} / \mathrm{L}$ (range 329-1052).

Methods: Vemurafenib was given starting at $550 \mathrm{mg} / \mathrm{m}^{2}$, twice daily which corresponds to the adult RP2D. Adverse events were graded using the NIH Common Terminology Criteria for Adverse Events (CTCAE) version 4.0. Central imaging review was performed. Pharmacokinetic sampling was performed. Conclusions: Vemurafenib has promising anti-tumor activity in recurrent BRAF V600E-positive brain tumors with manageable toxicity. A phase 2 study is ongoing (NCT01748149).

\section{INTRODUCTION}

$\mathrm{BRAF}^{\mathrm{V} 600 \mathrm{E}}$ is one of the most common oncogenic mutations in human tumors, found in $50 \%$ of metastatic melanomas, $10 \%$ of metastatic colon carcinomas, and $30 \%$ of papillary thyroid carcinomas [1]. This point mutation results in a constitutively active form of BRAF that functions as a monomer and is resistant to feedback inhibition [2]. Small molecule inhibitors that specifically target the $\mathrm{BRAF}^{\mathrm{V} 600 \mathrm{E}}$ kinase domain have been developed and have shown significant, albeit transient, activity in adult metastatic melanomas with BRAF ${ }^{\mathrm{V} 600 \mathrm{E}}$ mutations [3]. An unexpected side effect of this class of inhibitors is a high risk of secondary squamous cell carcinoma (keratoacanthoma). These occur in approximately $25 \%$ of treated adults and have been demonstrated to contain activating RAS mutations (or less frequently $\mathrm{NOTCH}$ or TGF deletions) and show growth stimulation through paradoxical activation of wild type RAF dimers by BRAF inhibitors [4].

Gliomas are the most common subgroup of pediatric brain tumors [5]. Children with low grade gliomas (WHO grade 1 and 2) have an excellent prognosis when these lesions can be totally resected, but often require adjuvant therapy when gross total resection cannot be achieved. Children with high grade gliomas (WHO grade 3 and 4) have a poor prognosis, despite aggressive multimodal therapy and no standard therapy, other than surgical resection and radiotherapy, has been established [6].

Until recently, adjuvant treatment for children with gliomas was limited to cytotoxic chemotherapy and radiation due to the lack of knowledge of the biological drivers of these tumors and a lack of available agents that could target such drivers [7]. Over the past ten years, many groups have demonstrated a high frequency of alterations in the RAS/RAF/MAPK pathway in pediatric gliomas. BRAF ${ }^{\mathrm{V} 600 \mathrm{E}}$ mutations, in particular, are found in $5 \%$ of malignant astrocytomas, $9 \%$ of pilocytic astrocytomas, $50 \%$ of gangliogliomas and $66 \%$ of pleomorphic xanthoastrocytomas [8]. Our group demonstrated significant anti-tumor efficacy of PLX4720 (tool compound analog of the $\mathrm{BRAF}^{\mathrm{V} 600 \mathrm{E}}$-specific inhibitor vemurafenib) in intracranial xenografts harboring BRAF ${ }^{V 600 E}$-mutant gliomas, while showing no efficacy against BRAF-wild type xenografts [9].
Herein we report on a multi-center phase 1 study conducted through the Pacific Pediatric Neuro-Oncology Consortium (PNOC) of vemurafenib in children $<18$ years of age with recurrent or progressive $\mathrm{BRAF}^{\mathrm{V} 600 \mathrm{E}}$ mutant brain tumors. At the time of trial development, there were no published reports of vemurafenib safety, efficacy, CNS penetration or pharmacokinetics in children with gliomas.

\section{RESULTS}

\section{Subject characteristics}

Among 19 eligible patients, one was not compliant with medications during the DLT period and therefore not fully evaluable for estimation of RP2D or PK analysis. Table 1 summarizes the subject characteristics. The most common histology was pilocytic astrocytoma $(n=10)$. Although this trial was open to both low and high-grade tumors, only patients with low-grade tumors enrolled in the safety study. While this trial was open at multiple sites, the relative scarcity of pediatric patients with recurrent $\mathrm{BRAF}^{\mathrm{V} 600 \mathrm{E}}$ mutant brain tumors led to expected relatively slow accrual.

\section{Toxicities}

The most common toxicity was maculopapular rash (Table 2). This is a known side effect of vemurafenib and responded well to holding the drug and supportive care. Two of the three patients initially treated at both Dose Level 0 and -1 had grade 3 rash and met DLT criteria. As these rashes resolved shortly after holding drug with appropriate supportive care and did not recur with restarting drug, we subsequently amended the study to exclude rash that resolved within 7 days with supportive care as a DLT. As a consequence, rather than further dose reductions, additional patients were treated at dose level -1 . Dose level -1 was subsequently declared safe without further rash and patients were then escalated back up to dose level 0 , which was also well tolerated and was determined as the RP2D.

One thirteen-year-old patient developed several facial lesions during Cycle 4 that were tissue confirmed squamous cell carcinoma (SCC). 
Table 1: Patient characteristics

\begin{tabular}{|c|c|c|}
\hline Age in years, at study enrollment, median (min, max) & \multicolumn{2}{|l|}{$9(3-17)$} \\
\hline Number of courses of vemurafenib: median (min, max) & \multicolumn{2}{|l|}{$23(4-64)$} \\
\hline Number of Prior Therapies & \multicolumn{2}{|c|}{ Number of patients } \\
\hline One & \multicolumn{2}{|l|}{4} \\
\hline Two & \multicolumn{2}{|l|}{4} \\
\hline \multirow[t]{2}{*}{ Three or more } & \multicolumn{2}{|l|}{11} \\
\hline & Number & Percentage \\
\hline \multicolumn{3}{|l|}{ Gender } \\
\hline Males & 9 & 47.4 \\
\hline Females & 10 & 52.6 \\
\hline \multicolumn{3}{|l|}{ Race } \\
\hline White, non-Hispanic & 14 & 73.7 \\
\hline Black & 2 & 10.5 \\
\hline Unknown & 3 & 15.8 \\
\hline \multicolumn{3}{|l|}{ Diagnosis } \\
\hline Astrocytoma (NOS) & 1 & 5.3 \\
\hline Fibrillary Astrocytoma & 1 & 5.3 \\
\hline Pilocytic Astrocytoma & 10 & 52.6 \\
\hline Ganglioglioma & 5 & 26.3 \\
\hline Pleomorphic Xanthoastrocytoma & 2 & 10.5 \\
\hline
\end{tabular}

Table 2: Number of grade 2 \& 3 toxicities probably, possibly or definitely attributable to vemurafenib

\begin{tabular}{|c|c|c|}
\hline Adverse Event & Grade 2 & Grade 3 \\
\hline Alanine aminotransferase increased & 0 & 1 \\
\hline Alkaline phosphatase increased & 1 & 1 \\
\hline Alopecia & 1 & 0 \\
\hline Anorexia & 2 & 0 \\
\hline Arthralgia & 3 & 0 \\
\hline Aspartate aminotransferase increased & 2 & 0 \\
\hline Blood bilirubin increased & 3 & 1 \\
\hline Bullous dermatitis & 1 & 0 \\
\hline Creatinine increased & 2 & 0 \\
\hline Diarrhea & 2 & 0 \\
\hline Dry skin & 3 & 0 \\
\hline Electrocardiogram QT corrected interval prolonged & 0 & 1 \\
\hline Erythema multiforme & 1 & 0 \\
\hline Erythroderma & 1 & 0 \\
\hline Fatigue & 2 & 0 \\
\hline Fever & 1 & 2 \\
\hline Gastrointestinal disorders - Acid reflux & 1 & 0 \\
\hline Headache & 1 & 0 \\
\hline Hypertension & 2 & 0 \\
\hline Hypophosphatemia & 1 & 0 \\
\hline
\end{tabular}


Investigations - Plantar hyperkeratosis with pain

Lymphocyte count decreased

\begin{tabular}{cc}
1 & 0 \\
2 & 1 \\
1 & 0 \\
1 & 0 \\
0 & 1 \\
1 & 0 \\
0 & 1 \\
0 & 1 \\
1 & 1 \\
12 & 10 \\
3 & 0 \\
1 & 0 \\
1 & 0 \\
1 & 0 \\
\hline
\end{tabular}

Mucositis oral

Nausea

Neoplasms benign, malignant and unspecified (incl cysts and polyps) - keratoacanthomas

Palmar-plantar erythrodysesthesia syndrome

Photosensitivity

Pneumonitis

Pruritus

Rash maculo-papular

Skin and subcutaneous tissue disorders - Dermatitis, heat rash, photoonycholysis

Skin infection

Somnolence

Weight loss

regression model using AUCs as a predictor of $\mathrm{PR}+\mathrm{CR}$ was not significant given the observed variability.

A total of 19 subjects underwent pharmacokinetic sampling. One subject with poor compliance was removed from the final analysis. The steady-state $\mathrm{AUC}_{0}$ median was $604 \mathrm{mg}^{*} \mathrm{~h} / \mathrm{L}$ (range 329-1052 mg*h/L). Pharmacokinetic analysis demonstrated a significant accumulation factor (approximately six-fold) over time with each vemurafenib dose. In an attempt to correlate exposure with response, patients were divided into those having stable disease (SD) versus those having PR or CR. Patients with SD had 11\% lower AUCss (586 mg*hr/L) compared to $\mathrm{PR}+\mathrm{CR}(657 \mathrm{mg} * \mathrm{hr} / \mathrm{L})$. However, a logistic
Patient outcomes are reported for the 19 patients treated. The median number of vemurafenib courses was 23 (range 3 to 63). Centrally reviewed best radiographic responses included $1 \mathrm{CR}, 5 \mathrm{PR}$, and 13 patients with SD (Figure 1). Solid tumor component was measured for determination of outcomes in 10 patients, with the remaining 9 patients with no measurable solid component undergoing measurement of solid/cystic

\section{Patient outcomes}

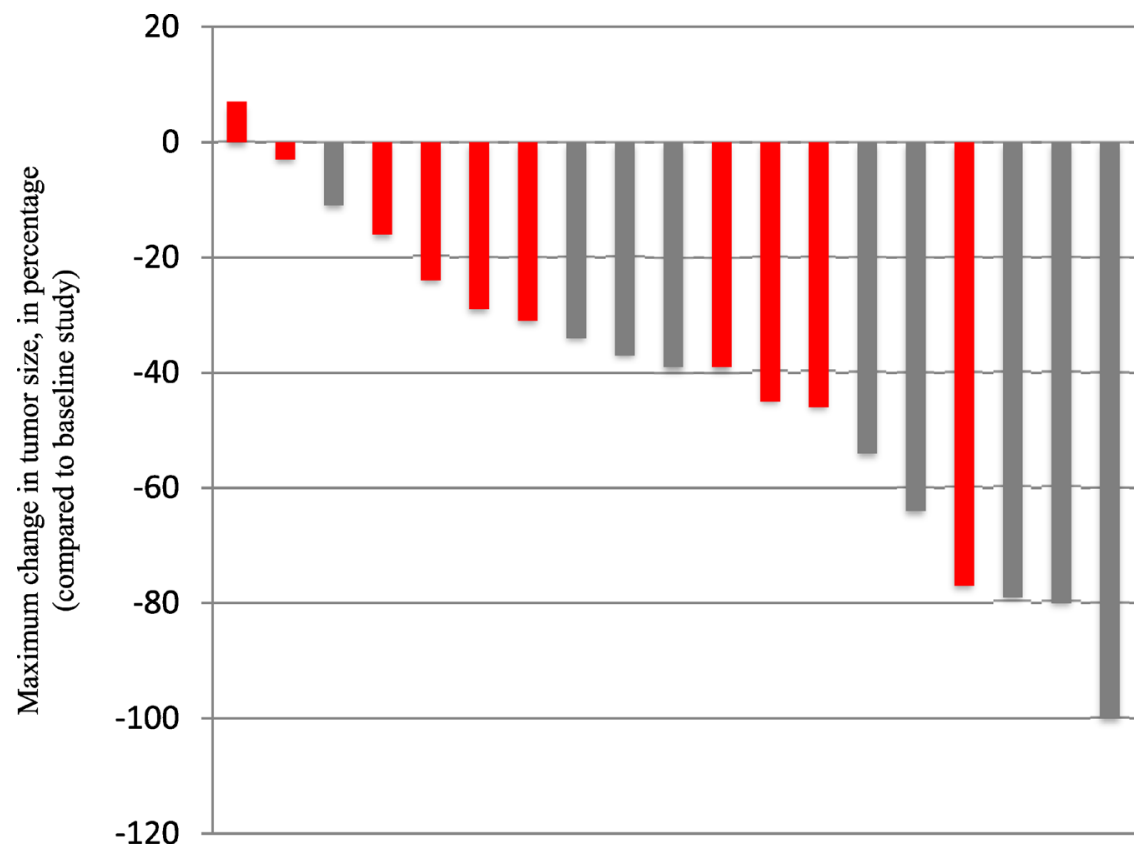

Figure 1: Depicted is the centrally reviewed "best response" per patient, based on the maximum change compared to on study MRI. Each bar represents a patient. Grey bars depict patients treated on dose level 0 and red bars show subjects treated on dose level-1. 
lesion for outcome determination. Figure 1 demonstrates best response percent decrease in tumor size during the course of treatment with vemurafenib. As shown in Table 3, responses were durable with some patients having continuous response for over 40 months. Cystic lesions appeared to decrease more in size compared to the solid lesions with vemurafenib therapy (Table 4). Interestingly, we found that 10 of the patients in our cohort who presented with contrast-enhancing tumors were found to develop loss of enhancement during treatment. Examples of radiographic responses are shown in Figure 2, with representative solid, cystic, and mixed solid/cystic lesions.

Of the 19 patients, only one patient (patient 10) progressed on therapy (Table 3 ). Three patients (patients 1,3 , and 6) came off drug because they had completed therapy (originally defined as 12 months). Eleven patients came off drug due to adverse events or patient decision. Four patients remain on therapy. Of the fourteen patients total that came off drug without progressive disease, only four progressed during the 12-month protocol-defined follow up period (Table 3).

\section{DISCUSSION}

The discovery of $\mathrm{BRAF}^{\mathrm{V} 600 \mathrm{E}}$ mutations in a wide spectrum of gliomas has led to optimism that these tumors can be therapeutically targeted by potent inhibitors of the mutant form of BRAF developed for the treatment of melanoma. Herein, we report that vemurafenib is safe in children with $\mathrm{BRAF}^{\mathrm{V} 600 \mathrm{E}}$ gliomas and has promising antitumor efficacy.

Vemurafenib was approved for the treatment of BRAF-mutant melanoma in 2011. Toxicities in adults with melanoma include rash, arthralgias and secondary malignancies (mostly SCC) [3]. The latter are of particular concern when considering this therapeutic approach for children, particularly for low grade tumors. In this phase 1 study, we found that the adult dose equivalent of 550 $\mathrm{mg} / \mathrm{m}^{2}$ was well tolerated in children with a similar safety profile seen in adult subjects. These results are similar to the small study of vemurafenib in adolescents with melanoma [10] and the recently reported pediatric experience with Langerhans Cell Histiocytosis [11]. While we encountered rash as a DLT in our initial cohort of patients, this was not seen once we amended our protocol with more universally used criteria for grading transient grade 3 non-hematologic toxicities in patients receiving BRAF inhibitors. Interestingly, one patient developed SCC while on vemurafenib therapy in our study. This patient did not have any concerning lesions at baseline and developed facial SCC during cycle 4 of therapy. Biopsy confirmed the diagnosis and genomic analysis of the SCC revealed TGF-beta receptor homozygous deletions, without any additional mutations affecting the RASA/RAF/MAPK pathway. TGF-beta signaling is known to have a tumor suppressive effect in skin stem cells and loss of TGF-beta signaling has been associated with SCC development in adults treated with BRAF inhibitors [4]. Of note, one of the six adolescents treated with vemurafenib in the melanoma study also developed an SCC [10].

Only one of the 19 patients who participated in this phase 1 study developed progression while on therapy. Four patients remain on therapy with a mean of $>23$ cycles of therapy. Our study found a high proportion of objective radiographic responses that were durable, with $1 \mathrm{CR}, 5 \mathrm{PRs}$, and 13 SDs as the centrally-reviewed best responses on therapy. The recently reported phase $\mathrm{I} / \mathrm{IIa}$ experience with the $\mathrm{BRAF}^{\mathrm{V} 600 \mathrm{E}}$ inhibitor dabrafenib in children with recurrent pediatric low grade glioma reported $1 \mathrm{CR}, 13 \mathrm{PR}, 11 \mathrm{SD}$ and two progressive diseases as best responses in a cohort of 32 patients $[12,13]$. This is of particular interest as both drugs have been shown to have poor CNS penetration in animal models [14]. It is important to point out that the dabrafenib study used the RANO criteria [15] to measure objective response, while our study used a modified RANO criteria which included tumor cysts in measurements.

One of the pressing issues facing the pediatric neuro-oncology community is the optimal duration of therapy for targeted agents. Of our fourteen patients that halted treatment for either toxicity, patient decision, or completion of therapy, four patients progressed during 12 months of follow up (Table 3). This suggests that while responses can be durable in some patients after halting drug, the ideal duration of therapy remains to be determined. Of note, three of our four patients that developed progressive disease off drug progressed within four months of stopping therapy and so careful early monitoring of patients who stop vemurafenib therapy is warranted.

The first reported trial of a BRAF inhibitor (sorafenib) for pediatric gliomas did not report any secondary skin cancer formation, but instead reported a significant stimulation of glioma tumor growth, which we did not observe in our cohort [16]. The underlying etiology of the sorafenib growth activation was thought to be the presence of the KIAA1549: BRAF fusion protein in the majority of enrolled patients. In contrast, our study restricted eligibility to patients with the $\mathrm{BRAF}^{\mathrm{V} 600 \mathrm{E}}$ mutation and specifically excluded patients with the KIAA1549: BRAF fusion, NF1, or any other known RAS-opathy. Appropriate subject selection and detailed preclinical characterization will be critical as targeted therapies such as vemurafenib will be integrated in the care of these children.

Pharmacokinetic analyses revealed similar drug exposure and kinetics as in adult patients [17]. It is well recognized there are often differences in pharmacodynamic endpoints between pediatrics and adults. Limitations exist when adult PK data and study endpoints are applied to a pediatric population particularly in early phase trials where 
Table 3: Patient Outcomes

\begin{tabular}{|c|c|c|c|c|c|c|c|c|}
\hline $\begin{array}{l}\text { Patient ID- } \\
\text { Pathology }^{1}\end{array}$ & $\begin{array}{c}\text { Enrolled } \\
\text { Dose } \\
(\mathrm{mg} / \mathrm{m} 2)\end{array}$ & $\begin{array}{c}\text { On } \\
\text { treatment } \\
\text { date }\end{array}$ & $\begin{array}{c}\text { Off } \\
\text { treatment } \\
\text { date }^{2}\end{array}$ & $\begin{array}{c}\text { Dose } \\
\text { Limiting } \\
\text { Toxicity }\end{array}$ & $\begin{array}{c}\text { Best } \\
\text { Response }^{3}\end{array}$ & $\begin{array}{l}\text { Number } \\
\text { of cycles }\end{array}$ & $\begin{array}{l}\text { Reason Off } \\
\text { Treatment }^{5}\end{array}$ & $\begin{array}{c}\text { Date of } \\
\text { progression }\end{array}$ \\
\hline $\begin{array}{l}1 \text { - low grade } \\
\text { astrocytoma NOS }\end{array}$ & 550 & $4 / 30 / 2014$ & $5 / 27 / 2015$ & yes & PR & 14 & $\begin{array}{l}\text { Completed } \\
\text { Therapy }\end{array}$ & $9 / 1 / 2015$ \\
\hline $\begin{array}{l}3 \text { - pilocytic } \\
\text { astrocytoma }\end{array}$ & 550 & $9 / 29 / 2014$ & $9 / 2 / 2015$ & no & $\mathrm{SD}$ & 12 & $\begin{array}{l}\text { Completed } \\
\text { Therapy }\end{array}$ & $\mathrm{n} / \mathrm{a}$ \\
\hline $\begin{array}{l}4 \text { - pilocytic } \\
\text { astrocytoma }\end{array}$ & 550 & $10 / 16 / 2014$ & + & yes & SD & 64 & $\mathrm{n} / \mathrm{a}$ & $\mathrm{n} / \mathrm{a}$ \\
\hline 5 - PXA & 420 & $12 / 4 / 2014$ & $8 / 13 / 2015$ & yes & SD & 9 & Adverse event & $\mathrm{n} / \mathrm{a}$ \\
\hline $\begin{array}{l}6 \text { - fibrillary } \\
\text { astrocytoma }\end{array}$ & 420 & $1 / 29 / 2015$ & $12 / 28 / 2015$ & no & SD & 12 & $\begin{array}{l}\text { Completed } \\
\text { Therapy }\end{array}$ & $\mathrm{n} / \mathrm{a}$ \\
\hline $\begin{array}{l}7 \text { - pilocytic } \\
\text { astrocytoma }\end{array}$ & 420 & $3 / 9 / 2015$ & $5 / 31 / 2016$ & yes & $\mathrm{SD}$ & 16 & $\begin{array}{c}\text { Patient } \\
\text { decision }\end{array}$ & $\mathrm{n} / \mathrm{a}$ \\
\hline $\begin{array}{l}10 \text { - } \\
\text { ganglioglioma }\end{array}$ & 420 & $8 / 20 / 2015$ & $9 / 15 / 2016$ & no & $\mathrm{SD}$ & 14 & $\begin{array}{c}\text { Disease } \\
\text { progression }\end{array}$ & $9 / 13 / 2016$ \\
\hline $\begin{array}{l}11 \text { - pilocytic } \\
\text { astrocytoma }\end{array}$ & 420 & $9 / 30 / 2015$ & $2 / 13 / 2019$ & no & $\mathrm{SD}$ & 44 & $\begin{array}{l}\text { Patient } \\
\text { decision }\end{array}$ & $\mathrm{n} / \mathrm{a}$ \\
\hline 12 - ganglioglioma & 420 & $12 / 8 / 2015$ & $2 / 11 / 2019$ & no & $\mathrm{SD}$ & 41 & $\begin{array}{c}\text { Patient } \\
\text { decision* }\end{array}$ & $4 / 19 / 2019$ \\
\hline $\begin{array}{l}13 \text { - pilocytic } \\
\text { astrocytoma }\end{array}$ & 420 & $12 / 31 / 2015$ & $4 / 8 / 2016$ & no & PR & 4 & Adverse event & $\mathrm{n} / \mathrm{a}$ \\
\hline $\begin{array}{l}\text { 14- pilocytic } \\
\text { astrocytoma }\end{array}$ & 420 & $4 / 14 / 2016$ & $5 / 17 / 2018$ & no & SD & 27 & $\begin{array}{l}\text { Patient } \\
\text { decision }\end{array}$ & $\mathrm{n} / \mathrm{a}$ \\
\hline 15 -ganglioglioma & 420 & $5 / 12 / 2016$ & + & no & SD & 43 & $\mathrm{n} / \mathrm{a}$ & $\mathrm{n} / \mathrm{a}$ \\
\hline $\begin{array}{l}16 \text { - } \\
\text { ganglioglioma }\end{array}$ & 420 & $6 / 15 / 2016$ & + & no & $\mathrm{SD}$ & 42 & $\mathrm{n} / \mathrm{a}$ & $\mathrm{n} / \mathrm{a}$ \\
\hline $\begin{array}{l}17 \text {-pilocytic } \\
\text { astrocytoma }\end{array}$ & 550 & $9 / 29 / 2016$ & + & no & PR & 38 & $\mathrm{n} / \mathrm{a}$ & $\mathrm{n} / \mathrm{a}$ \\
\hline 18 - PXA & 550 & $10 / 3 / 2016$ & $8 / 8 / 2018$ & no & $\mathrm{CR}$ & 24 & $\begin{array}{c}\text { Patient } \\
\text { decision* }\end{array}$ & $\mathrm{n} / \mathrm{a}$ \\
\hline $\begin{array}{l}19 \text { - pilocytic } \\
\text { astrocytoma }\end{array}$ & 550 & $11 / 10 / 2016$ & $8 / 31 / 2018$ & no & SD & 24 & $\begin{array}{c}\text { Patient } \\
\text { decision* }\end{array}$ & $\mathrm{n} / \mathrm{a}$ \\
\hline $\begin{array}{l}20 \text { - pilocytic } \\
\text { astrocytoma }\end{array}$ & 550 & $1 / 11 / 2017$ & $10 / 26 / 2018$ & no & PR & 23 & Adverse event & $12 / 11 / 2018$ \\
\hline $\begin{array}{l}21 \text { - pilocytic } \\
\text { astrocytoma }\end{array}$ & 550 & $2 / 22 / 2017$ & $4 / 25 / 2018$ & no & PR & 15 & Adverse event & $12 / 10 / 2018$ \\
\hline 22- ganglioglioma & 550 & $2 / 21 / 2017$ & $11 / 8 / 2018$ & no & SD & 22 & $\begin{array}{c}\text { Poor } \\
\text { compliance }\end{array}$ & $\mathrm{n} / \mathrm{a}$ \\
\hline
\end{tabular}

1. $\mathrm{NOS}=$ not otherwise specified; PXA $=$ Pleomorphic Xanthoastrocytoma

2. + Indicates that the patient remains on treatment as of $8 / 31 / 2019$

3. Best response by imaging. $\mathrm{PR}=$ partial response; $\mathrm{SD}=$ stable disease

4. Median number of cycles $=23$

5. Completion of protocol is defined as completing 12 cycles therapy.

*Patient decision to stop treatment with stable disease after 12 or more cycles; treatment was allowed to continue indefinitely as long as no toxicity, progression, or patient preference 
likelihood of success is low. Additionally, the historically applied maximum tolerated dose (based on toxicity) is often not equivalent to the maximum efficacious dose (based on biomarkers). Given the lack of data for reliable biomarkers in this rare disease population we specifically designed the study collection of new data (both PK and biomarkers) so that it can be combined with future trials to enhance sample size and better defining exposureresponse relationships to optimize the use of this drug in the pediatric population. While there was a correlation between drug exposure and radiographic response, this was not statistically significant in this cohort. Within the phase 2 study that is actively ongoing we will also assess if crushing vemurafenib for liquid formulation leads to similar exposure which is an important assessment when developing therapeutic options for children.

In summary, we report that vemurafenib is tolerable and efficacious in children with recurrent low grade gliomas

\section{Cystic Lesion} Baseline

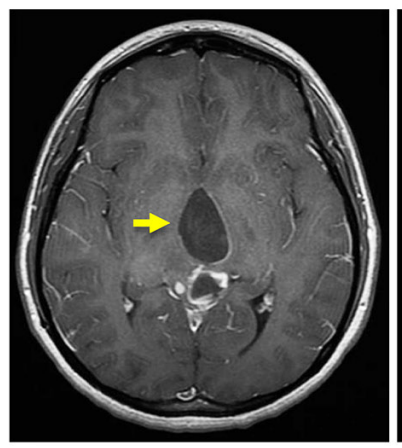

\section{Solid/Cystic Lesion} Baseline

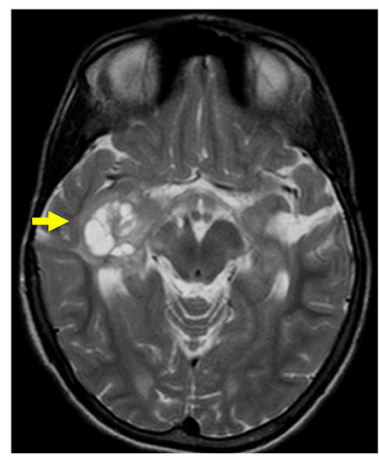

\section{Solid Lesion}

Baseline

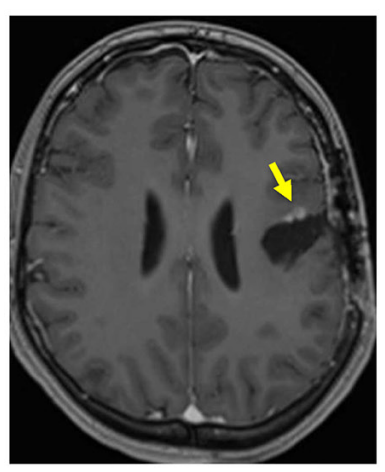

\section{2 months}

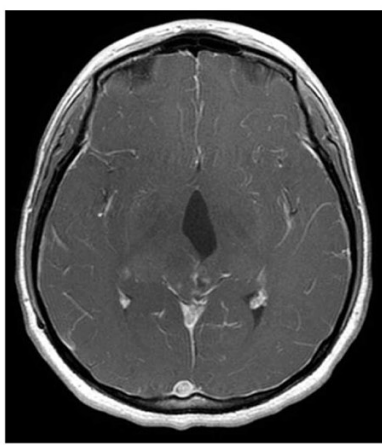

\section{2 months}

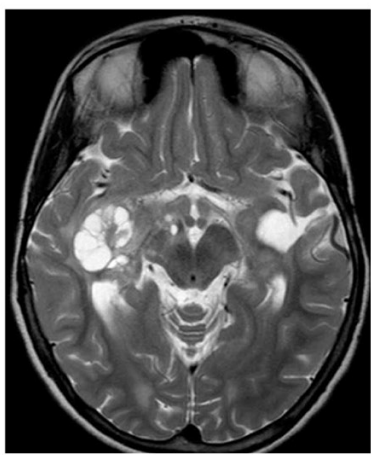

2 months

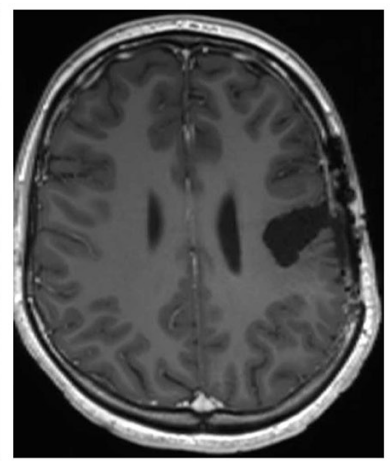

5 months

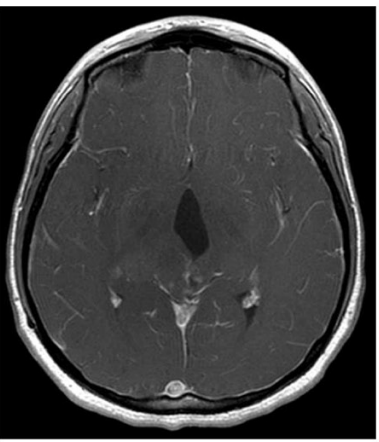

10 months

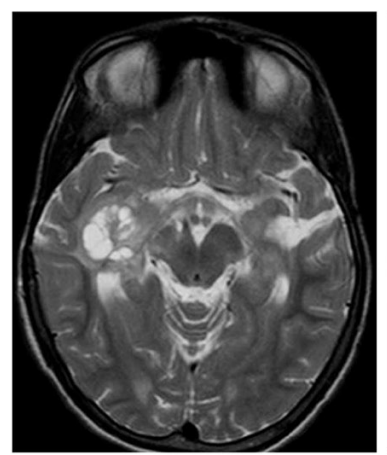

8 months

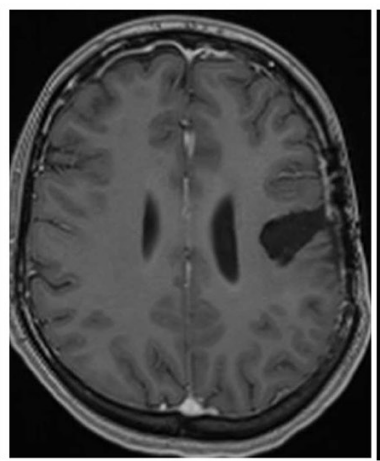

14 months

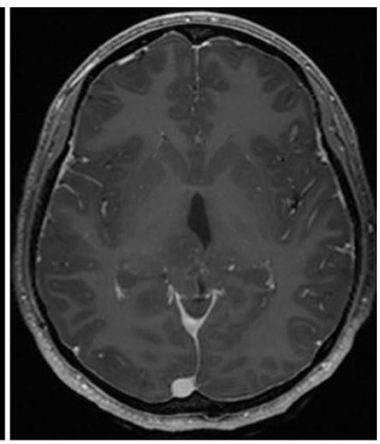

\section{4 months}

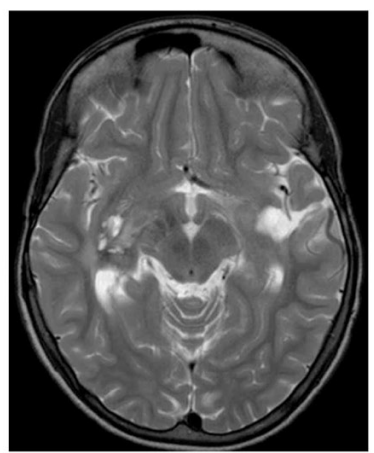

15 months

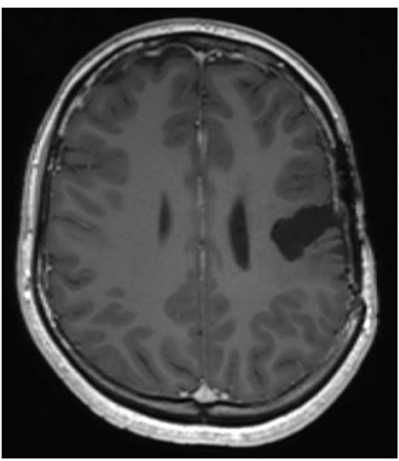

Figure 2: Depicted are representative images of subjects treated on PNOC-002 demonstrating. (A) regression of a contrast enhancing cystic lesion on a contrast, T1 weighted MR image over time; (B) regression of a solid/cystic lesion on a T2 weighted MR image over time; $(\mathbf{C})$ regression of a contrast enhancing solid lesion on a contrast, T1 weighted MR image over time. 
Table 4: Patients listed by their study numbers and shown are product of bi-dimensional tumor measurements for each tumor lesion. Some patients had more than one lesion

\begin{tabular}{|c|c|c|c|c|}
\hline Patient \# & Cystic & Solid/Cystic & Solid & Central review Best Response \\
\hline 1 & & -93 & -79 & PR \\
\hline 3 & -78 & -37 & & SD \\
\hline 4 & & & -11 & SD \\
\hline 5 & & -24 & & SD \\
\hline 6 & -12 & 7 & & SD \\
\hline 7 & -73 & & -29 & SD \\
\hline 10 & -89 & -39 & & SD \\
\hline 11 & & & -45 & SD \\
\hline 12 & & -32 & -16 & SD \\
\hline 13 & & -77 & & PR \\
\hline 14 & & -3 & & SD \\
\hline 15 & & & -46 & SD \\
\hline 16 & -92 & -100 & -31 & SD \\
\hline 17 & -100 & -80 & & PR \\
\hline 18 & & & -100 & $\mathrm{CR}$ \\
\hline 19 & & & -34 & SD \\
\hline 20 & & -82 & -54 & PR \\
\hline 21 & -72 & -64 & & PR \\
\hline 22 & & -39 & & SD \\
\hline
\end{tabular}

with $B R A F^{\mathrm{v} 600 \mathrm{E}}$ mutations. The RP2D is $550 \mathrm{mg} / \mathrm{m} 2$ twice daily. An efficacy cohort in patients under 25 years of age has recently completed accrual at the RP2D and will be reported separately once data matures. The upper age limit of the efficacy trial was extended to 25 years to accelerate our accrual due to the overall rarity of the disease being studied.

\section{MATERIALS AND METHODS}

\section{Eligibility}

The study was reviewed and approved by the Institutional Review Board of each participating institution. Verbal and written informed consent was obtained from all participants or their parents with assent obtained for the appropriately aged patients. Patients under 18 years of age who had a histologically confirmed diagnosis of a $\mathrm{BRAF}^{\mathrm{V} 600 \mathrm{E}}$-mutant primary brain tumor and Lansky or Karnofsky performance score $\geq 60$ were eligible. Confirmation of the BRAF ${ }^{\mathrm{V} 600 \mathrm{E}}$ mutation was required in a CLIA-approved laboratory, either by sequencing or immunohistochemistry. Either fresh biopsy or archival tissue were allowable for genotyping. Subjects must have had disease that failed at least one prior therapy (including radiation or systemic therapy) besides surgery and had to have evidence of measurable disease on MRI. There was no restriction for number of prior therapies. Subjects must have recovered from acute side effects of prior therapies and shown evidence of adequate bone marrow function (absolute neutrophil count $>1000$ cells/ul, hemoglobin $>8 \mathrm{gm} / \mathrm{dl}$ and platelets $>75,000 / \mathrm{ul}$ ), renal function within normal limits for age and liver function (total bilirubin $<1.5 \times$ ULN for age, ALT and AST $<2.5 \times$ ULN for age). Corticosteroids had to be on a stable or decreasing dose prior to treatment. The QTc on pre-treatment EKG had to be $<450$ msec. Patients must have been able to swallow tablets.

Children with active lesions suspicious for keratoacanthoma or cutaneous squamous cell carcinoma were excluded as were subjects with a known diagnosis of Neurofibromatosis Type 1 or any other RAS-opathy due to risk of paradoxical activation of tumor growth [18]. Further, prior exposure to a BRAF inhibitor constituted an exclusion criteria. 


\section{Treatment regimen, administration, and dose escalation design}

Vemurafenib (RO5185426; PLX4032) was supplied in $120 \mathrm{mg}$ and $240 \mathrm{mg}$ tablets by Genentech, Roche. Study drug was administered orally twice daily (BID) in 28day cycles. Doses were adjusted based on body surface area $\left(\mathrm{m}^{2}\right)$ prior to each cycle. The starting dose level (dose level 0) was $550 \mathrm{mg} / \mathrm{m}^{2}$ BID twice daily which was equivalent to the adult recommended phase 2 dose (RP2D) of $960 \mathrm{mg}$ based upon an average adult BSA of $1.73 \mathrm{~m}^{2}$. The maximum dose administered in this trial was capped at $960 \mathrm{mg}$ BID. Planned de-escalation dose levels included dose level -1 $420 \mathrm{mg} / \mathrm{m}^{2}$, dose level $-2330 \mathrm{mg} / \mathrm{m}^{2}$, dose level -3 $240 \mathrm{mg} / \mathrm{m}^{2}$ BID on a 28-day cycle and dose level $-4240 \mathrm{mg} / \mathrm{m}^{2}$ day $1-7$ and $15-21$. Dosing nomograms were used to accommodate the available pill sizes. Dose levels -1 and -2 were only considered for study subjects if the body surface area (BSA) was greater than $0.75 \mathrm{~m}^{2}$ and dose level -3 and -4 only when BSA was greater than $0.9 \mathrm{~m}^{2}$.

\section{Definition of dose limiting toxicity (DLT)}

Toxicities were graded based on the NCI Common Terminology Criteria for Adverse Events (CTCAE) version 4.0. Dose limiting toxicities (DLT) were based on adverse events occurring in the first 28 day cycle. Hematologic DLT was defined as any treatment related grade 4 hematologic toxicity with the exception of lymphopenia and anemia, grade 3 neutropenia with fever; or grade 3 thrombocytopenia. Non-hematologic DLTs were initially defined as any grade 3 or 4 related non-hematologic toxicity. The protocol was subsequently amended to exclude grade 3 rash, diarrhea, infection, fever, or photosensitivity that resolved to grade $\leq 2$ within 7 days of appropriate medical management in the DLT definition. This was based on additional Genentech/Roche trial experience supporting that these specific side effects can be well managed and should not constitute a DLT. Any related grade 2 non-hematological toxicity that persisted for more than 7 days and was considered sufficiently medically significant or sufficiently intolerable by patients to warrant treatment interruption and/ or dose reduction was also considered dose-limiting.

\section{Definition of response}

Disease evaluation was by MR imaging on $1.5 \mathrm{~T}$ or 3T clinical scanner that occurred at baseline followed by every 2-months assessments. Standard clinical sequences included 3 plane localizer, axial T2 weighted imaging, 3D fluid attenuated inversion recovery (FLAIR), and T1 weighted imaging without and with intravenous gadolinium. Subjects had the option to switch to every 3 months assessment after cycle 24. All images were anonymized prior to a retrospective central review by a study assigned neuroradiologist. Response criteria used were a modified version of the published "RANO" criteria [15]. Given that tumor cysts are commonly found in low grade gliomas in children, these were not excluded from measurements, as noted below. Measurable disease was defined as lesions that can be accurately measured in two dimensions with a minimum size of no less than double the slice thickness. T2 FLAIR sequences were used for disease assessment. All tumor measurements were recorded in millimeters or decimal fractions of centimeters and expressed as sum of products of largest diameter and perpendicular diameter. Tumor measurements over time were performed side by side in single session to maintain corresponding plane of view. Many of the lesions had both solid and cystic components. Tumor measurements included measurement of a solid portion of the tumor in lesions where the solid portion could be measured in isolation. In tumors with multiple cystic components that were inseparable from solid component, combined measurement of the "solid/cystic" lesion was performed. In tumors with only measurable cystic component, measurement of the cyst was performed. Previously irradiated lesions were considered non-measurable except in cases of documented progression of the lesion since the completion of radiation therapy. Complete response (CR) was defined as complete disappearance of the target lesion and no new lesions; partial response (PR) was defined as > $50 \%$ tumor reduction in product of bi-dimensional tumor measurements of solid lesions. Progressive disease (PD) was defined as an increase in product of bi-dimensional tumor measurements $>25 \%$ in a solid lesion or the appearance of a new lesion. For confirmation of CR and $\mathrm{PR}$, results needed to be sustained for 8 weeks.

\section{Pharmacokinetics}

\section{Pharmacokinetic sampling}

Serial blood samples for PK were collected on days 1,15 and 22 in cycle one of vemurafenib treatment. Whole blood samples were collected at 2, 4, 8, and 24 hours postdose on day 1 with additional trough levels obtained just prior to $(\mathrm{t}=0)$ and 1 -hour post dose on days 15 . PK collection was then repeated on day 22 with samples collected just prior to $(\mathrm{t}=0)$ and $2,4,8$, and 24 hours post-dose. Two milliliters of blood was collected at each sampling time through a venous catheter and placed in a heparinized tube for vemurafenib analysis. All samples, within 30 minutes of collection, were centrifuged at $3400 \mathrm{rpm}$ for 10 minutes at $4^{\circ} \mathrm{C}$, and the plasma removed and stored at $-80^{\circ} \mathrm{C}$ until analysis.

\section{Bioanalysis}

Plasma samples were analyzed by Covance Inc. (Princeton, New Jersey) using a validated reverse phase high performance liquid chromatography with mass spectrometry. The assay was linear in the range of 25.0 to $50,000 \mathrm{ng} / \mathrm{ml} \mathrm{RO5185426}$ (vemurafenib, PLX4032). 
Samples with concentrations above the upper limit of linearity were diluted and re-assayed. Samples with vemurafenib levels reported below the lower limit of quantification (LLOQ) were entered into the PK analysis as half the value of the LLOQ. Assay accuracy, intraday, and inter-day variability ranged from $90.4-105.9 \%$, $1.0-7.3 \%$, and $1.8-6.1 \%$, respectively.

\section{Pharmacokinetic analysis}

A nonlinear mixed effects modeling approach was used to describe vemurafenib time-plasma concentration data. A recent publication from the same authors described the population pharmacokinetic analysis in detail [19]. The non-linear mixed effect modeling approach has been used for characterizing the population pharmacokinetics in the past half-century [20]. Briefly, a one-compartment model with first-order absorption and elimination was applied, with a bodyweight-based allometric component added to all clearance and volume parameters using a fixed exponent of 0.75 and 1 , respectively. Between-occasion variability was included in the final covariate model using an exponential equation. The area-under-the-curve (AUC) for each patient was derived from the empirical Bayes estimate of individual clearance (CL) $(\mathrm{AUC}=\mathrm{Dose} / \mathrm{CL})$.

\section{Statistical design}

Due to the relative scarcity of $\mathrm{BRAF}^{\mathrm{V} 600 \mathrm{E}}$-mutant recurrent pediatric brain tumors and the expected difficulty in accrual for a traditional dose-escalation study, this study was conducted to determine the safety of the adult RP2D equivalent of $960 \mathrm{mg}$ BID (based on the average adult size of $1.73 \mathrm{~m}^{2}$ ), namely $550 \mathrm{mg} / \mathrm{m}^{2} /$ dose BID (dose level 0).

Three patients were initially enrolled at the dose level 0 and observed for toxicity during the dose-finding period (cycle 1). The dose escalation and de-escalation followed a modified $3+3$ design as follows: if more than 1 DLT occurred in the first 3 patients at dose level 0 , that dose was declared intolerable and subsequent patients were enrolled into the lower dose cohorts described earlier. If, on the other hand, 1 or fewer DLTs were observed at dose level 0, 3 additional patients were enrolled into that dose. Barring excessive toxicity, accrual to any dose level would be complete once 6 patients had been treated, and no more than 1 patient in a cohort of 6 experienced a DLT. There were 4 lower dose levels allowed, and dose escalation beyond dose level 0 was not allowed.

\section{ACKNOWLEDGMENTS}

We would like to thank all PNOC staff especially Kelly Hitchner, Anny Shai from the Neurosurgery tissue bank UCSF and all the PNOC PIs for their contribution and involvement in the study. We also want to thank all families and patients who participated in this trial.

\section{CONFLICTS OF INTEREST}

There are no conflicts of interest for any authors.

\section{FUNDING}

This trial was supported by funds from Genentech/ Roche, the PNOC Foundation, and the Pediatric Brain Tumor Foundation. TN and MP were supported by NIH/ NCI SPORE P50CA097257.

\section{REFERENCES}

1. Davies H, Bignell GR, Cox C, Stephens P, Edkins S, Clegg S, Teague J, Woffendin H, Garnett MJ, Bottomley W, Davis N, Dicks E, Ewing R, et al. Mutations of the BRAF gene in human cancer. Nature. 2002; 417:949-954. https:// doi.org/10.1038/nature00766. [PubMed]

2. Leicht DT, Balan V, Kaplun A, Singh-Gupta V, Kaplun L, Dobson M, Tzivion G. Raf kinases: Function, regulation and role in human cancer. Biochim Biophys Acta. 2007; 1773:1196-1212. https://doi.org/10.1016/j. bbamcr.2007.05.001. [PubMed]

3. Flaherty KT, Puzanov I, Kim KB, Ribas A, McArthur GA, Sosman JA, O’Dwyer PJ, Lee RJ, Grippo JF, Nolop K, Chapman PB. Inhibition of mutated, activated BRAF in metastatic melanoma. N Engl J Med. 2010; 363:809-819. https://doi.org/10.1056/NEJMoa1002011. [PubMed]

4. Cammareri P, Rose AM, Vincent DF, Wang J, Nagano A, Libertini S, Ridgway RA, Athineos D, Coates PJ, McHugh A, Pourreyron C, Dayal JH, Larsson J, et al. Inactivation of TGFbeta receptors in stem cells drives cutaneous squamous cell carcinoma. Nat Commun. 2016; 7:12493. https://doi.org/10.1038/ncomms12493. [PubMed]

5. Ostrom QT, Gittleman H, Truitt G, Boscia A, Kruchko C, Barnholtz-Sloan JS. CBTRUS statistical report: primary brain and other central nervous system tumors diagnosed in the united states in 2011-2015. Neuro Oncol. 2018; 20:iv1-86. https://doi.org/10.1093/neuonc/noy131. [PubMed]

6. Filbin MG, Sturm D. Gliomas in children. Semin Neurol. 2018; 38:121-130. https://doi.org/10.1055/s-0038-1635106. [PubMed]

7. PDQ Pediatric Treatment Editorial Board. Childhood Astrocytomas Treatment (PDQ(R)): Health Professional Version In: PDQ Cancer Information Summaries. Bethesda (MD): 2002

8. Schindler G, Capper D, Meyer J, Janzarik W, Omran H, Herold-Mende C, Schmieder K, Wesseling P, Mawrin C, Hasselblatt M, Louis DN, Korshunov A, Pfister S, et al. Analysis of BRAF V600E mutation in 1,320 nervous system tumors reveals high mutation frequencies in pleomorphic xanthoastrocytoma, ganglioglioma and extracerebellar pilocytic astrocytoma. Acta Neuropathol. 2011; 121:397-405. https://doi.org/10.1007/s00401-011-0802-6. [PubMed] 
9. Nicolaides TP, Li H, Solomon DA, Hariono S, Hashizume R, Barkovich K, Baker SJ, Paugh BS, Jones C, Forshew T, Hindley GF, Hodgson JG, Kim JS, et al. Targeted therapy for BRAFV600E malignant astrocytoma. Clin Cancer Res. 2011; 17:7595-7604. https://doi. org/10.1158/1078-0432.CCR-11-1456. [PubMed]

10. Chisholm JC, Suvada J, Dunkel IJ, Casanova M, Zhang W, Ritchie N, Choi Y, Park J, Das Thakur M, Simko S, Wan Rachel Tam N, Ferrari A. BRIM-P: A phase I, open-label, multicenter, dose-escalation study of vemurafenib in pediatric patients with surgically incurable, BRAF mutation-positive melanoma. Pediatr Blood Cancer. 2018; 65:e26947. https://doi.org/10.1002/ pbc.26947. [PubMed]

11. Donadieu J, Larabi IA, Tardieu M, Visser J, Hutter C, Sieni E, Kabbara N, Barkaoui M, Miron J, Chalard F, Milne P, Haroche J, Cohen F, et al. Vemurafenib for refractory multisystem langerhans cell histiocytosis in children: An international observational study. J Clin Oncol. 2019; 37:2857-2865. https://doi.org/10.1200/ JCO.19.00456. [PubMed]

12. Kieran MW, Bouffet E, Broniscer A, Cohen KJ, Geoerger B, Hansford JR, Hingorani P, Aerts I, Andre N, Bertozzi-Salamon A, Dunkel IJ, Hummel TR, Leary S, et al. Efficacy and safety results from a phase I/IIa study of dabrafenib in pediatric patients with BRAF V600-mutant relapsed refractory low-grade glioma. JCO. 2018; 36:10506. https://doi.org/10.1200/ JCO.2018.36.15_suppl.10506.

13. Kieran MW, Geoerger B, Dunkel IJ, Broniscer A, Hargrave DR, Hingorani P, Aerts I, Bertozzi AI, Cohen KJ, Hummel TR, Shen V, Bouffet E, Pratilas CA, et al. A phase 1 and pharmacokinetic study of oral dabrafenib in children and adolescent patients with recurrent or refractory BRAF V600 mutation-positive solid tumors. Clin Cancer Res. 2019; 25:7294-7302. https://doi.org/10.1158/1078-0432. CCR-17-3572. [PubMed]
14. Mittapalli RK, Vaidhyanathan S, Dudek AZ, Elmquist WF. Mechanisms limiting distribution of the threonineprotein kinase B-RaF(V600E) inhibitor dabrafenib to the brain: Implications for the treatment of melanoma brain metastases. J Pharmacol Exp Ther. 2013; 344:655-664. https://doi.org/10.1124/jpet.112.201475. [PubMed]

15. Wen PY, Macdonald DR, Reardon DA, Cloughesy TF, Sorensen AG, Galanis E, Degroot J, Wick W, Gilbert MR, Lassman AB, Tsien C, Mikkelsen T, Wong ET et al. Updated response assessment criteria for high-grade gliomas: response assessment in neuro-oncology working group. J Clin Oncol. 2010; 28:1963-72. https://doi.org/10.1200/ JCO.2009.26.3541. [PubMed]

16. Karajannis MA, Legault G, Fisher MJ, Milla SS, Cohen KJ, Wisoff JH, Harter DH, Goldberg JD, Hochman T, Merkelson A, Bloom MC, Sievert AJ, Resnick AC, et al. Phase II study of sorafenib in children with recurrent or progressive lowgrade astrocytomas. Neuro Oncol. 2014; 16:1408-1416. https://doi.org/10.1093/neuonc/nou059. [PubMed]

17. FDA Clinical Pharmacology Review. Available at: https:// www.accessdata.fda.gov/drugsatfda_docs/nda/2011/20242 9Orig1s000ClinPharmR.pdf.

18. Sievert AJ, Lang SS, Boucher KL, Madsen PJ, Slaunwhite E, Choudhari N, Kellet M, Storm PB, Resnick AC. Paradoxical activation and RAF inhibitor resistance of BRAF protein kinase fusions characterizing pediatric astrocytomas. Proc Natl Acad Sci USA. 2013; 110:59575962. https://doi.org/10.1073/pnas.1219232110. [PubMed]

19. Wang H, Long-Boyle J, Winger B, Nicolaides T, Mueller S, Prados M, Ivaturi V. Population Pharmacokinetics of Vemurafenib in Children with Recurrent/Refractory BRAF Gene V600E-Mutant Astrocytomas. J Clin Pharmacol. 2020. In Press.

20. Mould DR, Upton RN. Basic concepts in population modeling, simulation, and model-based drug development. CPT Pharmacometrics Syst Pharmacol. 2012; 1:1-4. https:// doi.org/10.1038/psp.2012.4. [PubMed] 